\title{
Sri Lankan
}

National Cancer Institute

\section{Source}

National Cancer Institute. Sri Lankan. NCI Thesaurus. Code C43672.

Denotes the inhabitants of Sri Lanka, a person from there, or their descendants elsewhere. 